\title{
A Dieldrin Case Study: Another Evidence of an Obsolete Substance in the European Soil Environment
}

\author{
Petros Tsiantas ${ }^{1}$, Evangelia N. Tzanetou ${ }^{1, *}$, Helen Karasali ${ }^{1, *(D)}$ and Konstantinos M. Kasiotis ${ }^{2}$ (D) \\ 1 Laboratory of Chemical Control of Pesticides, Department of Pesticides Control and Phytopharmacy, \\ Benaki Phytopathological Institute, 8 St. Delta Street, Kifissia, 14561 Athens, Greece; p.tsiantas@bpi.gr \\ 2 Laboratory of Pesticides' Toxicology, Department of Pesticides Control and Phytopharmacy, \\ Benaki Phytopathological Institute, 8 St. Delta Street, Kifissia, 14561 Athens, Greece; K.Kasiotis@bpi.gr \\ * Correspondence: ev.tzanetou@bpi.gr (E.N.T.); e.karassali@bpi.gr (H.K.); \\ Tel.: +30-210-8180209 (E.N.T.); +30-210-8180314 (H.K.)
}

Citation: Tsiantas, P.; Tzanetou, E.N.;

Karasali, H.; Kasiotis, K.M. A

Dieldrin Case Study: Another

Evidence of an Obsolete Substance in the European Soil Environment.

Agriculture 2021, 11, 314. https:/ /

doi.org/10.3390/agriculture11040314

Academic Editor:

Vasileios Antoniadis

Received: 25 February 2021

Accepted: 30 March 2021

Published: 3 April 2021

Publisher's Note: MDPI stays neutral with regard to jurisdictional claims in published maps and institutional affiliations.

Abstract: Soil constitutes a central environmental compartment that, due to natural and anthropogenic activities, is a recipient of several contaminants. Among them, organochlorine pesticides are of major concern, even though they have been banned decades ago in the European Union, due to their persistence and the health effects they can elicit. In the presented work, a gas chromatographic tandem mass spectrometric (GC-MS/MS) developed method was applied to soil samples after the suspected and potential use of formulations containing organochlorine active substance. One soil sample was positive to dieldrin at $0.018 \mathrm{mg} \mathrm{kg}^{-1}$. Predicted environmental concentration in soil (PECsoil) considering a single application of this active substance potentially attributed the finding in its past use. The subsequent health risk assessment showed negligible non-carcinogenic risk and tolerable carcinogenic risk. The latter signifies that repetitive and prolonged sampling can unveil the pragmatic projection of persistent chemicals' residues in the soil.

Keywords: soil; dieldrin; QuEChERS; GC-MS/MS; risk assessment

\section{Introduction}

Soil pollution is an outcome of both natural and anthropogenic activities [1]. It is apparent that subsequent land contamination can severely affect plants and vegetation, and remediation strategies are becoming an increasing need [2]. One of the most pronounced classes of soil pollutants are agrochemicals (pesticides and fertilizers). Notwithstanding the numerous consequences of soil contamination, the monitoring of pesticide residues in soil is not regulated at the EU level, in contrast to water governed by the EU Water Framework Directive [3]. In this regard, broad international studies on pesticide residues in soil are not that extensive when viewed from the perspective of the significance of this topic. In such cases, metabolites or degradation products may also be unknown. Among the soil contaminants of major significance are some obsolete organic chemicals, exemplified by the organochlorine pesticides (OCPs). OCPs are characterized by their high chemical stability, low solubility, lipophilicity, and volatility, and strong sorption by soil organic matter (SOM). Therefore, they persist in the environment for decades and inevitably bioconcentrate in food chains $[4,5]$.

In Europe, two global agreements safeguarding human health and the environment from these substances entered into force, the global Stockholm Convention (SC) on persistent organic pollutants (POPs) [6] and the 1998 Aarhus Protocol on POPs under the 1979 Geneva Convention on Long-range Transboundary Air Pollution (CLRTAP). Lately, within the frame of SC, another group of compounds has been included in the POPs list [7]. All European countries are parties to the SC, except Italy, which has not ratified it yet. The United Nations Environment Programme (UNEP)/Stockholm Convention on POPs initially listed 12 POPs (the dirty dozen) in 2004. Dieldrin and p,p'-dichlorodiphenyltrichloroethane 
(DDT) were among the first 12 POPs internationally prohibited through a United Nations treaty operational since 2004 [8].

More specifically, amongst OCPs, aldrin and dieldrin are archetypal representatives of this category. In the environment, aldrin is easily oxidized to its epoxide derivative, dieldrin, which is more resilient to chemical degradation [9]. From the 1950s to the 1970s, aldrin and dieldrin were widely used as insecticides in crops such as corn, cotton, and citrus fruits. Dieldrin was also used for mothproofing clothes and carpets. The U.S. Department of Agriculture banned aldrin and dieldrin in 1970. In 1972, however, United States Environmental Protection Agency (US EPA) approved aldrin and dieldrin to kill termites.

Although aldrin and dieldrin are not produced or used (for more than 30 years in the European Union), they are still detected in a plethora of environmental compartments such as soil, sediments, water, atmosphere, and organisms [10-13]. The latter can be attributed to their persistent chemical nature and the use of formulations containing them or respective counterfeit products. With regard to the soil factors and microbial community elements related with the in situ biodegradation of OCPs, there is limited knowledge, though soil properties and chemical degradation have been reviewed [14]. Nevertheless, it is assumed that SOM, a major factor influencing microbial biomass, impacts the biodegradation and total loss of the pollutants many decades after use.

The fate of POPs, i.e., the probable pathways in the environment after release, has been the objective of numerous studies. Biodegradation rates are slower when POPs are adsorbed by soil $[15,16]$ with the rate of desorption from soil organic matter (SOM) regulating degradation $[17,18]$. Dieldrin and DDT are fat-soluble and easily absorbed by hydrophobic organic matter [19-21]. Therefore, SOM seems to play a pivotal role in the degradation processes of POPs through adsorption, desorption, and its microbial load [17]. However, this relationship needs further elucidation to understand POPs degradation in agriculture soils in its entirety.

Reference and maximum levels in soils for no-longer authorized and highly persistent pesticides, such as DDTs, hexachlorocyclohexanes (HCHs), atrazine, and dieldrin, are encompassed into the legislation of some European countries [22]. In this respect, to evaluate the concordance with the POPs Convention within each country as well as on a regional and global basis, there is an increased need for laboratories in developing analytical methods to determine OCPs now and into the future.

Analytical methodologies for the analysis of OCPs and specifically dieldrin and aldrin are widely available [23] and are the result of a massive extent of environmental analytical method development and research on POPs over the past 50 years. The chemical analysis of OCPs is predominantly carried out by gas chromatography-mass spectrometry (GCMS). The utilization of gas chromatography (GC) with electron capture detection (ECD) is common because of its high resolution and good sensitivity. However, gas chromatographymass spectrometry (GC-MS) is also extensively employed for the determination of OCPs in complex matrices as it has better resolution and could give higher sensitivity and selectivity than the ordinary GC methods [24].

In the presented work, the presence of dieldrin in Greek soil samples after suspected use of such active substance is investigated. The latter was accomplished by applying a validated GC-MS/MS method covering both dieldrin and aldrin. Further on, human health risk assessment is appraised and discussed to present the potential impact of the found concentration on human health.

\section{Materials and Methods}

\subsection{Analytical Standards and Reagents}

High purity analytical standards (purity $>96 \%$ ) of aldrin and dieldrin, were purchased from Sigma Aldrich (Seelze, Germany). Triphenyl phosphate (TPP) of high purity ( $>99 \%)$ was added as an internal standard (IS) before chromatographic analysis and was obtained from Sigma Aldrich. Analytical standard stock solutions of aldrin and dieldrin, along 
with TPP solution, were prepared by gravimetric weighing of high purity standards to concentrations of about $1000 \mathrm{mg} \mathrm{L}^{-1}$ in acetone (pesticide residue grade) and stored at $-20{ }^{\circ} \mathrm{C}$. Standard solutions were equilibrated at room temperature and weighed to check for evaporation losses before use. Working solutions of aldrin and dieldrin, TPP, their mixtures, and spiked samples were prepared at different concentration levels, by appropriate dilutions of the stock solutions in acetone. All the standards and working solutions were stored in amber volumetric flasks at $-20{ }^{\circ} \mathrm{C}$ in the dark. Six working standard solutions for the determination of linearity were prepared by fortification of blank matrix extracts at concentration levels ranging from $0.005-0.5 \mathrm{mg} \mathrm{kg}^{-1}$. A soil sample free from the under study compounds was obtained from a field, without preceding history on pesticide use. This sample was analyzed in order to confirm that it did not contain aldrin and dieldrin and was considered a 'blank' sample.

LC-MS grade acetonitrile (ACN) and water were supplied by Fisher Scientific (Leicestershire, UK), while acetone suitable for GC and residual pesticide analysis from Carlo Erba (Milan, Italy).

\subsection{Description of the Study Area}

Although dieldrin and aldrin have not been used on arable plots in Greece since the 1970s, they have been detected in the edible parts of plants such as courgette/zucchini fruit (Cucurbita pepo L.) produced in some areas of Greece. It has been recognized that both compounds are readily taken up by zucchini fruits and furthermore it has been demonstrated that uptake of dieldrin and aldrin by courgette/zucchini fruit is the highest among others of the same or different plant family [25]. Therefore, measures need to be taken in order to recognize the potential source of aldrin and dieldrin in soil. The relative contribution of historic residues and/or the present illegal practice was studied as it was considered that the results would be of particular worth to considerate the sources of both compounds. Thus, Greek growers of courgette/zucchini fruit that would like to participate in the study were included in the soil analysis study in four sampling areas. The first area was from Episkopi Tegeas (X: 360932, Y: 4147676, Arcadia Prefecture, Greece) which is located in the central part of the Peloponnese, the second from Ksilokeriza Korinthos (Korinthia Prefecture, Greece) which is located in the south-central of Peloponnese, the third one from the Cycladic island of Kea (X: 525036.959, Y: 4161121.942, Cyclades Prefecture, Greece), and the last two from Beotika-Kalivakia Karditsa (X: 334095, Y: 4368363, located in the south-western Thessaly). Karditsa is primarily an agricultural area located in central Greece and consists of one of the most intensively cultivated and fertile agricultural plains in Greece. Courgette/zucchini fruit is one of the most significant crops in this region, thus two samples were taken. The fields included in the study were in flat areas with relatively high-input production. The climatic environments are characterized as warm and temperate with the following features: a dry season lasting from April to October and a rainy season approximately from November to March, accounting for approximately $65 \%$ of total annual rainfall. Temperature increases from January (average minimum: $5{ }^{\circ} \mathrm{C}$ and maximum $15^{\circ} \mathrm{C}$ ) to August (average minimum: $20^{\circ} \mathrm{C}$ and maximum $45^{\circ} \mathrm{C}$ ).

Soil samples were collected randomly from the surface horizon $(0-15 \mathrm{~cm})$. At each field, three soil sub-samples were gathered using soil auger and bulked in order to obtain a characteristic sample for each plot. Samples were stored in clean plastic bags and labeled properly. The collected samples were then transported to the lab (Benaki Phytopathological Institute) within the same day of the sampling in ice box, for keeping low temperature conditions. Upon receiving, soil samples were air dried at room temperature (avoiding light), homogenized, and finally sieved through a $2 \mathrm{~mm}$ sieve. Then samples were frozen at $-40{ }^{\circ} \mathrm{C}$ till extraction and further analysis.

\subsection{Sample Preparation}

For the sample preparation, the quick, easy, cheap, effective, rugged, and safe (QuEChERS) approach was embraced, which was adjusted for soil samples using a methodology 
similar to the one depicted by Silva and coworkers [26]. In short, soil samples were left to reach the ambient temperature and after thorough mixing, a subsample of $5( \pm 0.1) \mathrm{g}$ was placed into a $50 \mathrm{~mL}$ screw cap centrifuge tube, fortified with appropriate amount of the IS solution, mixed with $10 \mathrm{~mL}$ of water (HPLC grade) and $10 \mathrm{~mL}$ of acetonitrile (HPLC grade) and shaken rigorously. Then, $4.0 \mathrm{~g}$ of magnesium sulfate anhydrous, $1.0 \mathrm{~g}$ of sodium chloride, and $1.0 \mathrm{~g}$ of trisodium citrate de-hydrate and $0.5 \mathrm{~g}$ of disodium hydrogencitrate sesquihydrate were added, and the mixture was agitated (end-over-end) for 1 $\mathrm{min}$. After centrifugation at $3000 \mathrm{rpm}$ for $5 \mathrm{~min}, 6 \mathrm{~mL}$ of the supernatant were collected in a separate screw cap centrifuge tube containing $150 \mathrm{mg}$ of primary secondary amine (PSA) sorbent and $900 \mathrm{mg}$ of magnesium sulfate. The mixture was shaken rigorously for $30 \mathrm{~s}$ and then centrifuged for $5 \mathrm{~min}$ at $3000 \mathrm{rpm}$. Finally, the cleaned-up extract was analyzed by GC-MS/MS.

\subsection{Gas Chromatography-Mass Spectrometry-GC-QqQ-MS Analysis}

The chromatographic analysis for the determination of dieldrin and aldrin was carried out on a Shimadzu triple quadrupole mass spectrometer GCMS-TQ8040NX, composed of a GC-2030 gas chromatograph and an autosampler AOC-6000 (CTC Analytics) using a $10 \mu \mathrm{L}$ syringe. Separations were performed on a MEGA-5 HT $(30 \mathrm{~m} \times 0.25 \mathrm{~mm} \times 0.25 \mu \mathrm{m})$ (MEGA S.r.l., Legnano, Italy) capillary column. Helium was used as the carrier gas at a flow rate of $1.69 \mathrm{~mL} \mathrm{~min}^{-1}$. The column oven temperature program initiated from $50{ }^{\circ} \mathrm{C}$ at which was held for $1 \mathrm{~min}$, increased to $125^{\circ} \mathrm{C}$ at a rate $25^{\circ} \mathrm{C} \mathrm{min}-1$, then increased to $300{ }^{\circ} \mathrm{C}$ at a rate of $10^{\circ} \mathrm{C} \mathrm{min}^{-1}$, finally kept constant for an additional $15 \mathrm{~min}$. The triple quadrupole (QqQ) mass spectrometer was operated in EI-MS/MS mode in multiple reaction monitoring (MRM) data acquisition mode. The interface and source of ionization temperatures were 250 and $230{ }^{\circ} \mathrm{C}$, respectively. For the MS/MS experiments, Argon $99.999 \%$ was used as a collision gas and the collision cell pressure was set at $1.7 \mathrm{mTorr}$. The detector voltage was set at $0.6 \mathrm{kV}$, relative to the tuning result. Three MRM transitions were monitored for each analyte (quantitation ions, $m / z 241$ for dieldrin, and $m / z 191$ for aldrin, MRM chromatograms shown in Figures 1 and S2). The total GC analysis time was $36.5 \mathrm{~min}$, employing a solvent delay of $4 \mathrm{~min}$ to protect the mass spectrometer filament. Aldrin and dieldrin eluted at 12.15 and 14.07 min correspondingly.

\subsection{Analytical Method Validation}

The method efficiency was evaluated by studying the analytical method quality criteria, comprising linearity, matrix effect (ME), limit of quantitation LOQ, accuracy, and precision as recommended by international guidelines [27,28]. Criteria for compound identification included the matching of retention times of the analytes in the samples and the standard with a tolerance of $\pm 0.1 \mathrm{~min}$, the use of same quantitation ion following the acceptable MRM ratio tolerance (see Figure 1 for MRM transitions of dieldrin and TPP), including a signal to noise ratio $\mathrm{S} / \mathrm{N}>3: 1$. Precision (as repeatability, relative standard deviation (RSD) \%) and accuracy had been assessed by recovery experiments with the use of the 'blank soil' at three fortification levels $\left(0.005,0.01\right.$, and $0.05 \mathrm{mg} \mathrm{kg}^{-1} \mathrm{dry}$ weight) and analysis in quintuplicate. Recoveries between $80-120 \%$ with RSD\% lower than $20 \%$ were considered as reasonable according to the European Commission's DirectorateGeneral for Health and Food Safety (DG SANTE) guidelines on pesticide residues analytical methods [28]. The specificity of the method was assessed by analyzing a "procedure blank" and a "processed blank" soil spiked at the lowest concentration level measured. The sensitivity of the method was assessed by method's limit of detection (LOD) and LOQ. The validated LOQs were determined as the lowest validated spike level (expressed in $\mathrm{mg} \mathrm{kg}^{-1}$ dry weight), meeting the method performance acceptability criteria as regards to recovery and its corresponding RSD\% [28]. 
Dieldrin standard solution (A)

Dieldrin in sample (B)
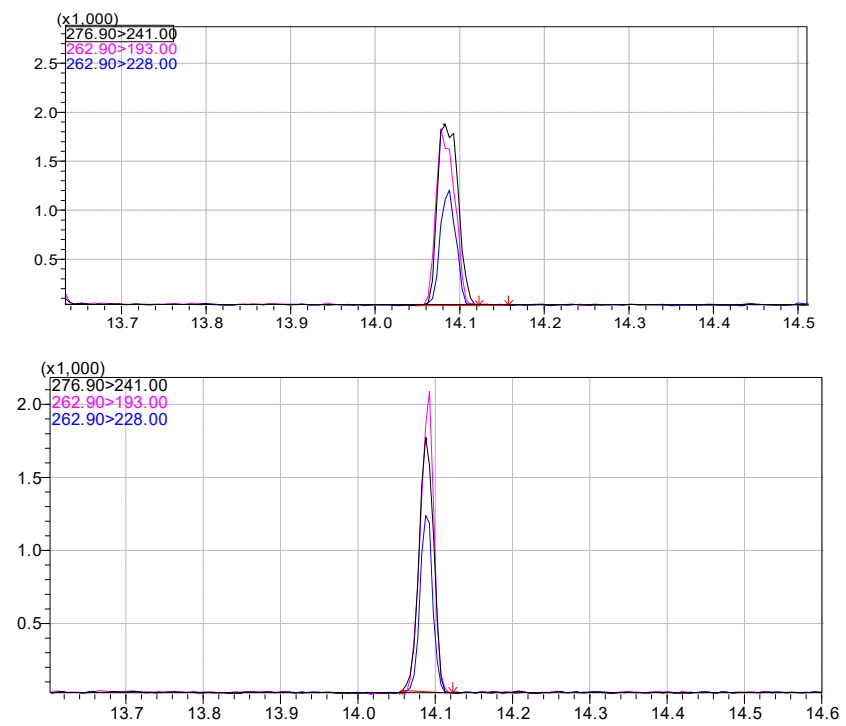

TPP (C)

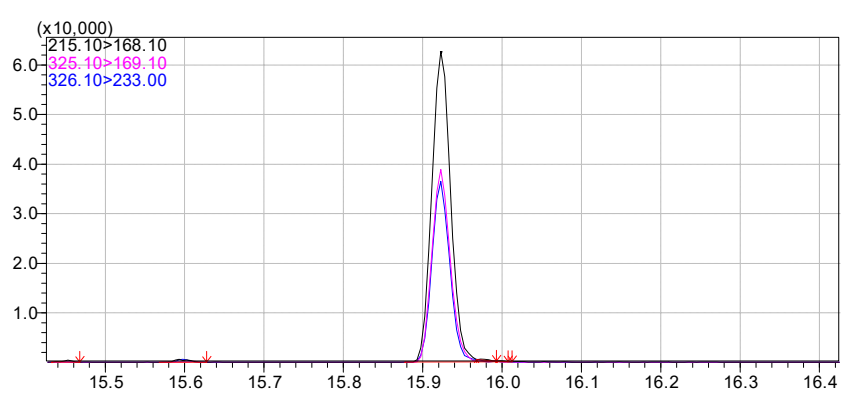

Figure 1. MRM chromatograms of dieldrin standard solution at $0.005 \mathrm{mg} \mathrm{L}^{-1}(\mathbf{A})$, dieldrin in positive sample (B), and TPP internal standard solution at $0.02 \mathrm{mg} \mathrm{L}^{-1}(\mathbf{C})$.

\subsubsection{Linearity-Matrix Effect}

Linearity of response was estimated by the use of solvent and matrix-matched calibration curves at six concentration levels and with triplicate analysis at each level: 0.005, 0.01, $0.02,0.05,0.1,0.5 \mathrm{mg} \mathrm{kg}^{-1}$. Regression and residuals analysis demonstrated an excellent linear relationship as the correlation coefficients $\left(\mathrm{r}^{2}\right)$ were better than 0.995 for both analytes (Table 1). The residuals were calculated to ensure that the fit of the calibration is satisfactory and within the concentration range of the compound identified. The assessment of the $\mathrm{ME} \%$ was estimated by the comparison of the slopes of calibration curves dissolved in the acetone (extraction solvent) and the matrix matched standard curves according to Equation (1) [29]:

$$
\mathrm{ME} \%=100 \times[1-(\text { solvent slope }) /(\text { matrix slope })] .
$$

The ME was confirmed for both analytes, thus quantification was performed with matrix-matched standard calibration curves. 
Table 1. Regression parameters, $L O Q$, recovery, and precision for dieldrin and aldrin in soil matrix.

\begin{tabular}{|c|c|c|c|c|}
\hline$(\mathrm{a} \pm \mathrm{Sa})$ & $(\mathrm{b} \pm \mathrm{Sb})$ & $\mathrm{r}$ & \multicolumn{2}{|c|}{ LOQ $\left(\mathrm{mg} \mathrm{kg}^{-1}\right)$} \\
\hline $5992.7 \pm 221.2$ & $10,596.2 \pm 188.8$ & 0.9992 & \multicolumn{2}{|c|}{0.005} \\
\hline \multirow{2}{*}{ Active substance } & \multirow{2}{*}{$\begin{array}{l}\text { Spiking level } \\
\left(\mathrm{mg} \mathrm{kg}^{-1}\right)\end{array}$} & \multirow{2}{*}{$\begin{array}{l}\text { Mean Recovery } \% \\
\pm \mathrm{RSD} \%, N=5\end{array}$} & \multicolumn{2}{|c|}{ Precision $(\mathrm{RSD} \%), N=5$} \\
\hline & & & $\left(\mathrm{RSD}_{\mathrm{r}} \%\right)$ & $\left(\mathrm{RSD}_{\mathrm{R}} \%\right)$ \\
\hline \multirow{3}{*}{ Dieldrin } & 0.005 & $85.2 \pm 11.2$ & 8.0 & 10.4 \\
\hline & 0.01 & $102.4 \pm 6.4$ & 4.8 & 9.2 \\
\hline & 0.05 & $81.1 \pm 5.9$ & 6.3 & 5.9 \\
\hline$(\mathrm{a} \pm \mathrm{Sa})$ & $(b \pm S b)$ & $\mathrm{r}$ & \multicolumn{2}{|c|}{$\mathrm{LOQ}\left(\mathrm{mg} \mathrm{kg}^{-1}\right)$} \\
\hline $12,982.1 \pm 188.4$ & $10,096.1 \pm 107.9$ & 0.9996 & \multicolumn{2}{|c|}{0.005} \\
\hline \multirow{2}{*}{ Active substance } & \multirow{2}{*}{$\begin{array}{l}\text { Spiking level } \\
\left(\mathrm{mg} \mathrm{kg}^{-1}\right)\end{array}$} & \multirow{2}{*}{$\begin{array}{l}\text { Mean Recovery } \% \\
\pm \mathrm{RSD} \%, N=5\end{array}$} & \multicolumn{2}{|c|}{ Precision $(\mathrm{RSD} \%), N=5$} \\
\hline & & & $\left(\mathrm{RSD}_{\mathrm{r}} \%\right)$ & $\left(\mathrm{RSD}_{\mathrm{R}} \%\right)$ \\
\hline \multirow{3}{*}{ Aldrin } & 0.005 & $80.1 \pm 7.7$ & 7.0 & 10.2 \\
\hline & 0.01 & $93.4 \pm 5.9$ & 3.2 & 7.2 \\
\hline & 0.05 & $77.1 \pm 3.8$ & 5.5 & 6.9 \\
\hline
\end{tabular}

\subsubsection{Accuracy, Limit of Quantification, and Precision}

The accuracy of the method was established by determining recoveries from spiked blank samples at three fortification levels, at $0.005,0.01$, and $0.05 \mathrm{mg}$ dieldrin (and aldrin) $\mathrm{kg}^{-1}$ dry weight. Recovery was satisfactory at the three study levels, varying from $81-102 \%$ (for both analytes advise Table 1). All experiments were implemented five times and the RSD\% was calculated. The LOQ was defined as the lowest validated concentration level of $0.005 \mathrm{mg} \mathrm{kg}^{-1}$ soil dry weight for dieldrin and aldrin.

A soil sample without previous record of pesticide use was used for recovery experiments. This sample was previously analyzed to ensure that it did not contain dieldrin and aldrin, then used as a blank soil sample. The blank soil sub-samples for recovery experiments were treated as follows: $5.0 \mathrm{~g}$ of the sample (blank soil sample) was placed in a $50 \mathrm{~mL}$ centrifuge tube along with appropriate quantity of the standard of the desired dieldrin (and aldrin) concentration in acetone. It was homogenized by mechanical shaking for $15 \mathrm{~min}$ for better analyte distribution and the bulk of the solvent was left to evaporate at ambient temperature and controlled by weight. This is a procedure able to imitate weathered residues [30]. Afterwards, spiked samples were extracted as described above in paragraph 2.3. "Sample Preparation". Samples were quantified with matrix-matched standard calibration. Method precision was evaluated through repeatability of the instrumental method; therefore, intra and inter-day RSD were determined. Thus, the method precision was expressed as the RSD\% for replicate analysis $(N=5)$ on the same day (repeatability, $\left.\mathrm{RSD}_{\mathrm{r}} \%\right)$, and analysis on five different days $\left(N=5\right.$, reproducibility, $\left.\mathrm{RSD}_{\mathrm{R}} \%\right)$.

\subsection{Predicted Environmental Concentration in Soil ( $\left.P E C_{\text {soil }}\right)$}

The calculation of the PECsoil $\left(\mathrm{mg} \mathrm{kg}^{-1}\right)$ for a single dieldrin application was based on the rationale and equations depicted in the FOrum for Co-ordination of pesticide fate models and their USe (FOCUS) group document [31] assisted by the spreadsheet calculator available from the Dutch Board for the Authorization of Plant Protection Products and Biocides (Ctgb) [32]. Indicatively, for maximum $\mathrm{PEC}_{\text {soil }}$, the equation below (Equation (2)) was used:

$$
P E C_{\text {soil, } \max }=A n \times \frac{1-p_{n}}{100 \times S_{d} \times S_{b d}},
$$

where $A n$ : application rate $\left(\mathrm{g}_{\text {dieldrin }} \mathrm{ha}^{-1}\right), p_{n}$ : the fraction intercepted by the crop canopy, $S_{d}$ : the soil depth $(\mathrm{cm}), S_{b d}$ : the soil bulk density $\left(\mathrm{g} \mathrm{cm}^{-3}\right)$. 
To proceed to the respective calculations, a scenario with certain hypotheses was embraced. In this respect, for dieldrin, a uniform distribution in the superior soil layer and an initial mixing depth at $5 \mathrm{~cm}$, a $p_{n}$ equal to zero, the mean, bibliographically reported, $A n$ of $9 \mathrm{~kg}$ a.s. ha ${ }^{-1}$ [33], a dry $S_{b d}$ of $1.5 \mathrm{~g} \mathrm{~cm}^{-3}$, and a worst case soil degradation half-life $\left(\mathrm{DT}_{50}\right)$ of 1825 days [34] were contemplated.

\subsection{Health Risk Assessment}

Risk assessment was based on recommendations by US EPA [35] and published work investigating human health risks as a consequence of soil contamination [36]. To delineate the non-carcinogenic human health risk provoked by potential exposure to any organochlorine (e.g., dieldrin) on soil concentration, the average daily doses $(A D D, \mathrm{mg} / \mathrm{kg} /$ day) considering specific routes of exposure were determined following the depicted equations (Equations (3)-(6)):

$$
\begin{gathered}
A D D_{\text {intake }}=\frac{C_{\text {soil }} \times B A F \times F I R \times E F \times E D \times C F}{B W \times A T}, \\
A D D_{\text {ingest }}=\frac{C_{\text {soil }} \times S I R \times E F \times E D \times C F}{B W \times A T}, \\
A D D_{\text {dermal }}=\frac{C_{\text {soil }} \times S A \times E F \times E D \times A F \times A B S \times C F}{B W \times A T}, \\
A D D_{\text {inhale }}=\frac{C_{\text {soil }} \times E F \times E D \times 10^{3}}{P E F \times A T},
\end{gathered}
$$

where $C_{\text {soil }}$ : the concentration in soil (mg/ $\mathrm{kg}$ ), BAF: is the bioaccumulation factor of dieldrin from soil to foodstuff, FIR: the daily intake rate of food by inhabitants (mg/day), EF: exposure frequency (days/yr), ED: exposure duration (yr), CF: conversion factor $(\mathrm{kg} / \mathrm{mg})$, $B W$ : body weight $(\mathrm{kg}), A T$ : average lifetime (days), SIR: soil ingestion rate (mg/day), $S A$ : soil surface area $\left(\mathrm{cm}^{2} /\right.$ day), $A F$ : soil adherence factor $\left(\mathrm{mg} / \mathrm{cm}^{2}\right), A B S$ : pesticide fraction absorbed dermally from the soil (no unit), PEF: particulate emission factor $\left(\mathrm{m}^{3} / \mathrm{kg}\right)$.

To determine the non-carcinogenic risk, the target hazard quotient $(T H Q)$ was further assessed. The calculation of $T H Q$ was based on the following equation (Equation (7)):

$$
T H Q=\frac{A D D}{R f D},
$$

in which $R f D$ is the oral reference dose $(\mathrm{mg} / \mathrm{kg} /$ day) (respective reference concentration for inhalation exposure is not assessed under the integrated risk information system of US-EPA).

Cumulative health risk was assessed by calculating the hazard index $(\mathrm{Hi})$. The latter was derived from the summation of all separate THQs $(k=$ number of exposure pathways regarded) (Equation (8)):

$$
H I=\sum_{k=1}^{n} T H Q_{k}
$$

For the carcinogenic risk assessment, Equations (1) and (4) were used intact, using the appropriate value of AT. All values used are presented in the Supplementary Material (Table S1). With regard to $A D D_{\text {ingest }}$ and $A D D_{\text {dermal }}$, the following Equations (9) and (10), were used:

$$
\begin{gathered}
A D D_{\text {ingest }}=\frac{C_{\text {soil }} \times S I R_{a a} \times E F \times C F}{A T}, \\
A D D_{\text {dermal }}=\frac{C_{\text {soil }} \times E F \times S D C F_{a a} \times A F \times A B S \times C F}{A T},
\end{gathered}
$$

where $S I R_{a a}$ is the age-adjusted soil ingestion rate (mg per year $\mathrm{kg}^{-1}$ day $\left.^{-1}\right)$ and $S D C F_{a a}$ is the age-adjusted soil dermal contact factor (mg per year $\mathrm{kg}^{-1} \mathrm{day}^{-1}$ ). 
In this regard, the individual and the total cancer risk (CR) was assessed using the following equations for the individual exposure pathway and the summation of all routes, including inhalation (Equations (11)-(13)):

$$
\begin{gathered}
C R_{k}=A D D_{k} \times C S F, \\
C R_{I n h}=A D D_{i n h} \times I U R, \\
C R=\sum_{k=1}^{n} C R_{k}+C R_{i n h}
\end{gathered}
$$

where $\operatorname{CSF}\left(\left(\mathrm{mg} \mathrm{kg}^{-1} \mathrm{day}^{-1}\right)^{-1}\right)$ is the cancer slope factor (oral slope factor for ingestion, $C S F_{o}$, and dermal slope factor $\left.C S F_{d}=C S F_{o} \times A B S_{G I}\right), A B S_{G I}=$ pesticide fraction absorbed in the gastrointestinal tract), IUR $\left(\left(\mathrm{mg} \mathrm{m}^{-3}\right)^{-1}\right)$, inhalation unit risk.

$C R$ was considered negligible when it was below $1 \times 10^{-6}$, and likely harmful when above $1 \times 10^{-4}$. Values within the range $1 \times 10^{-6}$ to $1 \times 10^{-4}$ indicate an acceptable or tolerable risk.

\section{Results and Discussion}

\subsection{Analytical Method Performance}

The analytical method was fit for purpose, as unveiled by the metrics of its validation. The calculated intra-day RSDs fluctuated between $6.3 \%$ and $8.0 \%$, and the inter-day RSD ranged from $5.9 \%$ to $10.0 \%$ (Table 1 ) and considered acceptable.

ME varied both for dieldrin and aldrin from 7-10\%, hence it was negligible (for blank soil extract MRM chromatograms see Figure 1).

\subsection{Soil Samples Results}

Dieldrin and aldrin belong to the group of OCPs and are characterized by their persistence in the environment, especially in soil compartment, and are still present due to past uses [37]. Dieldrin is a long-lived oxidation breakdown product of aldrin, as the latter quickly breaks down into dieldrin in soil, characteristically in some days [38] (from 20-100 days [39]). Mathematical models assessed that aldrin would degrade by $69 \%$ to dieldrin in 81 days when applied within $15 \mathrm{~cm}$ from the soil surface [39]. Aldrin's $\mathrm{DT}_{50}$ was assessed to be approximately 110 days when applied to soil at a rate of $1.1-3.4 \mathrm{~kg} \mathrm{ha}^{-1}$, with 95\% loss in 3 years [39]. Factors such as sunlight and soil microorganisms additionally modify aldrin to dieldrin, thus dieldrin could be found in agricultural areas where aldrin was originally released [40]. Thus, soil concentration of dieldrin is a cumulative consequence of the historic use of both compounds. Dieldrin is immensely persistent in soil, and by means of bioaccumulation it is concentrated countless times as it moves up the food chain. Its n-octanol/water partition coefficient $\left(\log \mathrm{K}_{\mathrm{ow}}\right)$ ranges from 4.32 to 6.2, suggesting also high potentials for bioaccumulation [39]. Dieldrin persistence is due to its enormously low volatility and low solubility in water $\left(0.14 \mathrm{mg} \mathrm{L}^{-1}\right)$, resulting in a high affinity for fat [34]. Dieldrin residence time is often greater than 7 years, hence, the United States Environmental Protection Agency (US EPA) had determined the adsorption coefficient $\left(\mathrm{K}_{\mathrm{oc}}=190.546 \mathrm{~mL} \mathrm{~g}^{-1}\right)$ and based on that value is considered a non-mobile active substance.

Dieldrin has been detected in the edible parts of courgette/zucchini fruit, thus the relative contribution of historic residues and/or the present illegal practice should be assessed. It is critical to conduct a countrywide study on the occurrence of aldrin and dieldrin in soils in order to estimate their origin and further estimate their associated potential health risks because they have been restricted for many years. Hence, in this study, sampling was conducted in five agricultural soils of four main plains, where these compounds were extensively used, across Greece. The aim was to (a) identify the potential source of the identified compounds, (b) to establish a background level of the identified compounds, and (c) estimate the potential health risks of the identified compounds. It is expected that these results will assist in better understanding the residue occurrence 
after their usage following restriction or ban for many years. In addition, these results will provide powerful support for pollution control and management by decision-makers.

To the best of our knowledge, the residue levels of aldrin and dieldrin in agricultural soils had not been investigated previously in Greece. Dieldrin was detected in one of the five samples collected recently from the areas described in paragraph 2.2. 'Description of the study area' at a concentration of $0.018 \pm 0.009 \mathrm{mg} \mathrm{kg}^{-1}$ dry weight $(n=3$, for MRM chromatogram see Figure 1B), but aldrin was not detected in any of the tested samples. This finding can partly be explicated by the fact that apart from being a pesticide, it is also formed as a metabolite of aldrin [41]. Nevertheless, since the metabolism of chemicals (and pesticides in particular) in soil is governed by a plethora of physicochemical factors (e.g., $\mathrm{pH}$, organic carbon content) [42], leading to inconsistent behavior of chemicals in soil, it is risky to exclude exhaustive metabolism of aldrin to dieldrin. The PEC calculations, under the specific scenario and in a projection of several decades, displayed that the found concentration was possibly an outcome of past use (for PECsoil decline curve, see Figure 2). More specifically, the $\mathrm{PEC}_{\text {soil }}\left(0.016 \mathrm{mg} \mathrm{kg}^{-1}\right)$ approximated the positive sample's found concentration, 17,500 days ( 48 years) after its initial application (for all $\mathrm{PEC}_{\text {soil }}$ values see Table S2).

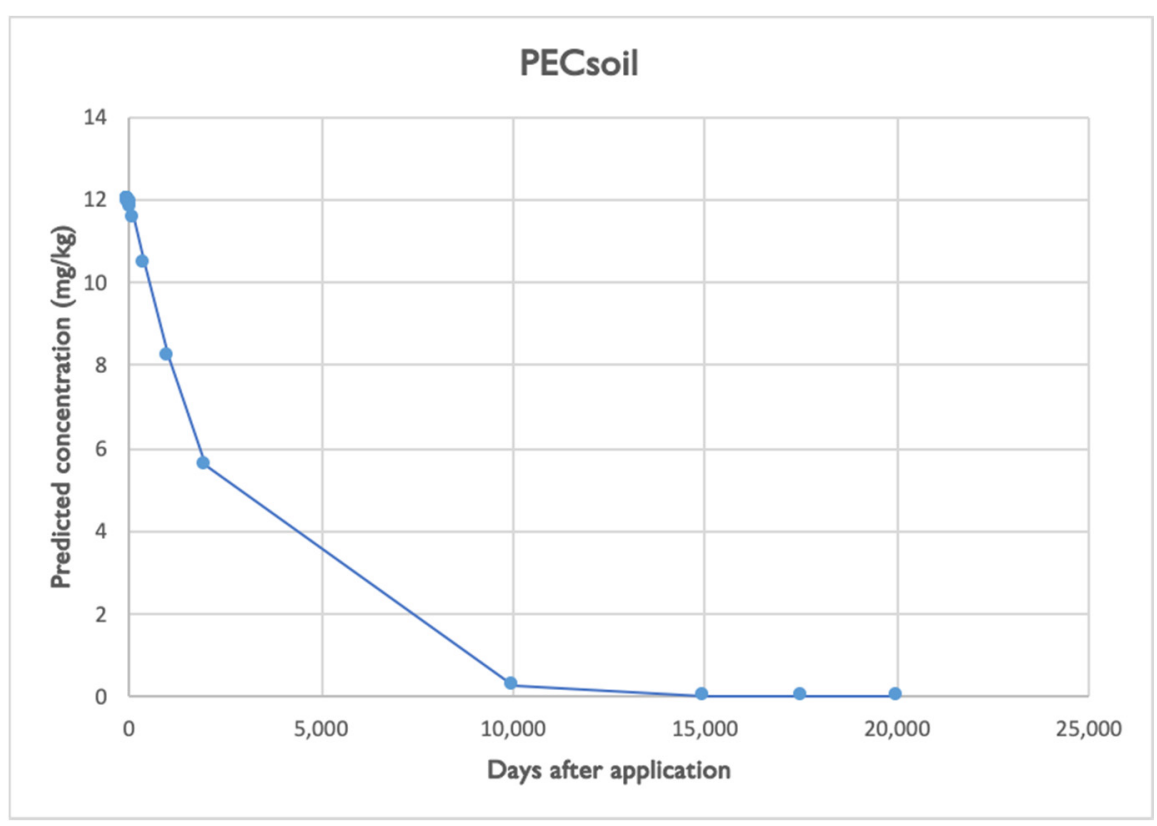

Figure 2. PECsoil decline curve.

In another reading, the presented finding is worrying considering the ban of this active substance. More specifically, several countries, in the context of soil quality criteria, have already set a threshold value (permissible concentrations) for dieldrin in soil ranging from 0.0005 to $0.1 \mathrm{mg} \mathrm{kg}^{-1}$ dry weight, depending on the type of soil, its depth, and country that produced the data [22]. This comparison indicates that the found concentration can be alarming since it falls within the specified range. Nevertheless, further conclusions should consider all parameters, such as soil quality, uses, and proximity to specific population groups, which were not the scope of the presented study.

Nowadays, OCPs are used only in some developing countries to control especially malaria. Therefore, OCPs detection in European soil generally underpins three elements: (1) the use of dieldrin in the specific area long time ago (as possibly in the presented case), (2) its transport from other areas where old or existing applications took place, and (3) the possibility of use of counterfeit/illegal formulations containing it. Greece is the crossroad of two continents, possessing extensive borders, therefore it cannot be excluded that counterfeit products can be introduced in its area, though authorities are proactive and apply appropriate controls to avoid such phenomena. More specifically, literature 
designates that the residues of obsolete chemicals in several environmental compartments and organisms (e.g., birds and European eels), are largely attributed to their historical application and to small amounts of such chemicals used recently $[43,44]$. Italy was the largest consumer of aldrin and dieldrin in Europe between the 1940s to the 1970s before the use of these agricultural chemicals was prohibited in 1988 [45]. Indicatively, recent studies showed these chemicals to be pervasive in the soils from the Benevento region, in southern Italy [46]. Dieldrin was the most ample chemical, exhibiting a concentration of $0.012 \mathrm{ng} \mathrm{g}^{-1}$ (arithmetic mean (AM)) and a detection frequency (DF) of $17.2 \%$, followed by aldrin with an AM of $0.0042 \mathrm{ng} \mathrm{g}^{-1}$ and a DF of $12.5 \%$, and endrin with an AM of $0.0033 \mathrm{ng} \mathrm{g}^{-1}$ and a DF of 6.25\% [46]. Qu et al. (2017) verified the secondary distribution pattern of some legacy OCs in the soils of the Campanian plain, which encouraged further research related to the role of soil as a reemission source. The exchange of OCPs across the air-soil interface is an additional significant process for figuring out the environmental fate and risks of these chemicals.

In China, aldrin and dieldrin were never industrially manufactured and used as an agricultural pesticide in China [47]. Nevertheless, in a Chinese study, aldrin was found in 21 of 58 investigated samples with levels ranging from 0.70 to $8.5 \mathrm{ng} \mathrm{g}^{-1}$ for all of the soils except one, which contained $17 \mathrm{ng} \mathrm{g}^{-1} \mathrm{dw}$. The concentrations of detectable dieldrin in 29 samples ranged from 0.34 to $5.0 \mathrm{ng} / \mathrm{g}$. Similar results were observed in a previous study which investigated the concentration of OCPs in surface water and sediments in Qiantang River, the largest river of Zhejiang, and found residues of dieldrin in most water and sediment samples. The wide distribution of never used aldrin and dieldrin possibly indicated a continuous input into China by long-range atmospheric transport.

\subsection{Human Risk Assessment}

The health risk assessment was based on considerations of the dietary and non-dietary pathways/sources. Consequently, after the determination of concentration in soil, the average daily doses were evaluated using bibliographic equations. Some of the values are dependent on the individual active substance (in this case dieldrin), such as the BAF of dieldrin from soil to foodstuff. Concerning BAF, and since to our knowledge none such value was available for soil/vegetables, an admission was taken. Thus, BAF value was retrieved from a dieldrin study performed in Sevilla (Spain, with similar climate to Greece) on corn $[48,49]$. As the soil was sampled from zucchini cultivations, health risk assessment considered the human daily intake of vegetables (adults and adolescents) as registered in the European Union. Therefore, the ADDs via the dietary pathway were determined taking into account food grown in soil, and the non-dietary pathway, incorporating inhalation, soil ingestion, and dermal contact [36]. The calculations of the hazard quotients and the respective hazard index demonstrated negligible risk (see Table 2 for all respective results for adults and children).

On the contrary, the respective calculations (see Table 2) for the CR positioned it (principally attributed to the CRintake value) in the range of tolerable risk $\left(\mathrm{CR}=3.18 \times 10^{-5}\right.$ for adults, $C R=3.68 \times 10^{-5}$ for children), which indicates that further data and prolonged monitoring in the same agricultural field and potentially to nearby areas are required in cases where such concentrations are evidenced. 
Table 2. Health risk assessment estimates.

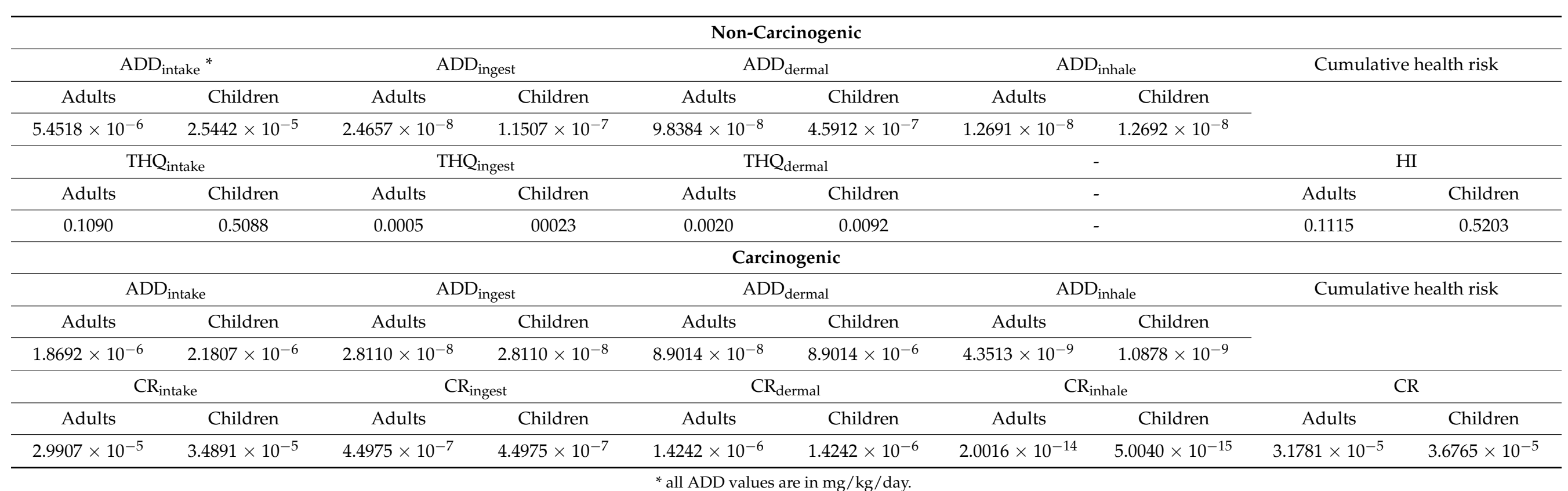

* all ADD values are in $\mathrm{mg} / \mathrm{kg} /$ day. 


\section{Conclusions}

The presented work belongs to a series of analytical methods developed to detect and quantify pesticide residues is soil. The implementation of a GC-MS/MS method focused on organochlorine pesticides disclosed the presence of dieldrin, an active substance banned many decades ago in Europe. Hence, this finding is worrying considering both the prohibited character of this chemical and the potential health effects that can be provoked after exposure of humans and other organisms to it. As a further step, the non-carcinogenic and carcinogenic risk assessment demonstrated negligible and acceptable risk, respectively. Future actions include the adequate multiresidue monitoring of soils on national basis to safeguard compliance with the POPs Convention key elements, and the constant notification of authorities when such findings occur.

Supplementary Materials: The following are available online at https:/ /www.mdpi.com/article/10 .3390 /agriculture11040314/s1, Figure S1: MRM chromatograms of dieldrin (A) and aldrin (B) in blank soil sample, Figure S2: MRM chromatogram of aldrin standard solution in acetone (at $0.005 \mathrm{mg} \mathrm{L}^{-1}$ ), Table S1: Parameters used in exposure cancer and no-cancer risk assessments, Table S2: Dieldrin PECsoil $(\mathrm{mg} / \mathrm{kg})$ values in the range of 0-20,000 days, after application.

Author Contributions: Conceptualization, H.K.; methodology, H.K., E.N.T., P.T., K.M.K.; software, P.T., K.M.K.; validation, H.K., E.N.T., P.T.; formal analysis, H.K., E.N.T., K.M.K.; investigation, H.K., E.N.T., P.T., K.M.K.; resources, H.K.; data curation, P.T., E.N.T., K.M.K.; writing-original draft preparation, E.N.T., H.K.; writing—review and editing, H.K., E.N.T., K.M.K.; visualization, E.N.T., H.K.; supervision, H.K., E.N.T.; project administration, H.K.; funding acquisition, H.K. All authors have read and agreed to the published version of the manuscript.

Funding: This research received no external funding.

Data Availability Statement: All data generated or analysed during this study are included in this published article [and its supplementary information files].

Conflicts of Interest: The authors declare no conflict of interest.

\section{References}

1. Pico, Y.; Alvarez-Ruiz, R.; Alfarhan, A.H.; El-Sheikh, M.A.; Alobaid, S.M.; Barcelo, D. Uptake and accumulation of emerging contaminants in soil and plant treated with wastewater under real-world environmental conditions in the Al Hayer area (Saudi Arabia). Sci. Total Environ. 2019, 652, 562-572. [CrossRef] [PubMed]

2. Koul, B.; Taak, P. Soil Pollution: Causes and Consequences. In Biotechnological Strategies for Effective Remediation of Polluted Soils; Koul, B., Taak, P., Eds.; Springer: Singapore, 2018; pp. 1-31.

3. Directive. Directive 2000/60/EC of the European Parliament and of the Council of 23 October 2000 establishing a framework for Community action in the field of water policy. Off. J. Eur. Communities 2000, 327, 1-72.

4. Muir, D.C.G.; Norstrom, R.J.; Simon, M. Organochlorine Contaminants in Arctic Marine Food-Chains-Accumulation of Specific Polychlorinated-Biphenyls and Chlordane-Related Compounds. Environ. Sci. Technol. 1988, 22, 1071-1079. [CrossRef] [PubMed]

5. Olsson, A.; Valters, K.; Burreau, S. Concentrations of organochlorine substances in relation to fish size and trophic position: A study on perch (Perca fluviatilis L.). Environ. Sci. Technol. 2000, 34, 4878-4886. [CrossRef]

6. UNEP. Regionally Based Assessment of Persistent Toxic Substances—Global Report; United Nations Environment Programme, Châtelaine: Geneva, Switzerland, 2011; p. 207.

7. Stockholm-Convention. Stockholm Convention on Persistent Organic Pollutants (POPs). 2011. Available online: http://chm. pops.int/ (accessed on 10 January 2021).

8. United Nations Environment Programme (UNEP). Stockholm Convention on Persistent Organic Pollutions (POPs); Châtelaine GE: Switzerland, 2017; Available online: http:/ / chm.pops.int (accessed on 10 January 2021).

9. Shegunova, P.; Klanova, J.; Holoubek, I. Residues of organochlorinated pesticides in soils from the Czech Republic. Environ. Pollut. 2007, 146, 257-261. [CrossRef] [PubMed]

10. Umulisa, V.; Kalisa, D.; Skutlarek, D.; Reichert, B. First evaluation of DDT (dichlorodiphenyltrichloroethane) residues and other Persistence Organic Pollutants in soils of Rwanda: Nyabarongo urban versus rural wetlands. Ecotoxicol. Environ. Safe 2020, 197. [CrossRef] [PubMed]

11. Krohn, C.; Jin, J.; Ryan, J.; Fabijanski, P.; Franks, A.E.; Tang, C.X. Composition of soil organic matter drives total loss of dieldrin and dichlorodiphenyltrichloroethane in high-value pastures over thirty years. Sci. Total Environ. 2019, 691, 135-145. [CrossRef] 
12. Khuman, S.N.; Vinod, P.G.; Bharat, G.; Kumar, Y.S.M.; Chakraborty, P. Spatial distribution and compositional profiles of organochlorine pesticides in the surface soil from the agricultural, coastal and backwater transects along the south-west coast of India. Chemosphere 2020, 254. [CrossRef]

13. Eudoxie, G.D.; Mathurin, G.; Lopez, V.; Perminova, O. Assessment of pesticides in soil from obsolete pesticides stores: A Caribbean case study. Environ. Monit. Assess. 2019, 191. [CrossRef]

14. Biswas, B.; Qi, F.J.; Biswas, J.K.; Wijayawardena, A.; Khan, M.A.I.; Naidu, R. The Fate of Chemical Pollutants with Soil Properties and Processes in the Climate Change Paradigm-A Review. Soil Syst. 2018, 2, 51. [CrossRef]

15. Calderbank, A. The Occurrence and Significance of Bound Pesticide-Residues in Soil. Rev. Environ. Contam. T 1989, 108, 71-103.

16. Jenkinson, D.S.; Rayner, J.H. Turnover of Soil Organic-Matter in Some of Rothamsted Classical Experiments. Soil Sci. 1977, 123, 298-305. [CrossRef]

17. Ren, X.Y.; Zeng, G.M.; Tang, L.; Wang, J.J.; Wan, J.; Liu, Y.N.; Yu, J.F.; Yi, H.; Ye, S.J.; Deng, R. Sorption, transport and biodegradation-An insight into bioavailability of persistent organic pollutants in soil. Sci. Total Environ. 2018, 610, 1154-1163. [CrossRef] [PubMed]

18. Zhang, N.; Yang, Y.; Tao, S.; Liu, Y.; Shi, K.L. Sequestration of organochlorine pesticides in soils of distinct organic carbon content. Environ. Pollut. 2011, 159, 700-705. [CrossRef]

19. Gevao, B.; Semple, K.T.; Jones, K.C. Bound pesticide residues in soils: A review. Environ. Pollut. 2000, 108, 3-14. [CrossRef]

20. Xing, B.S.; Pignatello, J.J. Dual-mode sorption of low-polarity compounds in glassy poly(vinyl chloride) and soil organic matter. Environ. Sci. Technol. 1997, 31, 792-799. [CrossRef]

21. Sharom, M.S.; Miles, J.R.W.; Harris, C.R.; Mcewen, F.L. Behavior of 12 Insecticides in Soil and Aqueous Suspensions of Soil and Sediment. Water Res. 1980, 14, 1095-1100. [CrossRef]

22. Carlon, C.; D'Alessandro, M.; Swartjes, F. Derivation Methods of Soil Screening Values in Europe. A Review and Evaluation of National Procedures towards Harmonization; European Commission, Joint Research Centre: Ispra, Italy, 2007; p. 306.

23. Muir, D.; Sverko, E. Analytical methods for PCBs and organochlorine pesticides in environmental monitoring and surveillance: A critical appraisal. Anal. Bioanal. Chem. 2006, 386, 769-789. [CrossRef]

24. Fatoki, O.S.; Awofolu, R.O. Methods for selective determination of persistent organochlorine pesticide residues in water and sediments by capillary gas chromatography and electron-capture detection. J. Chromatogr. A 2003, 983, 225-236. [CrossRef]

25. Otani, T.; Seike, N.; Sakata, Y. Differential uptake of dieldrin and endrin from soil by several plant families and Cucurbita genera. Soil Sci. Plant Nutr. 2007, 53, 86-94. [CrossRef]

26. Silva, V.; Mol, H.G.J.; Zomer, P.; Tienstra, M.; Ritsema, C.J.; Geissen, V. Pesticide residues in European agricultural soils-A hidden reality unfolded. Sci. Total Environ. 2019, 653, 1532-1545. [CrossRef]

27. ICH. Validation of Analytical Procedures: Text and Methodology Q2(R1). Available online: http://www.ich.org/fileadmin/ Public_Web_Site/ICH_Products/Guidelines/Quality/Q2_R1/Step4/Q2_R1_Guideline.pdf (accessed on 12 November 2020).

28. SANTE/12682/2019. Guidance Document on Analytical Quality Control and Method Validation Procedures for Pesticides Residues Analysis in Food and Feed; European Commission: Brussels, Belgium, 2019.

29. Pano-Farias, N.S.; Ceballos-Magana, S.G.; Muniz-Valencia, R.; Gonzalez, J. Validation and assessment of matrix effect and uncertainty of a gas chromatography coupled to mass spectrometry method for pesticides in papaya and avocado samples. $J$. Food Drug Anal. 2017, 25, 501-509. [CrossRef]

30. Diez, C.; Barrado, E.; Marinero, P.; Sanz, M. Orthogonal array optimization of a multiresidue method for cereal herbicides in soils. J. Chromatogr. A 2008, 1180, 10-23. [CrossRef]

31. FOCUS-1997. Soil Persistence Models and EU Registration. Available online: https://esdac.jrc.ec.europa.eu/public_path/u891/Soil\%20 persistence \%20models\%20and\%20EU\%20registration $\backslash \mathrm{T} 1 \backslash$ textquoteright $\% 20 \% 281997 \% 29$.pdf (accessed on 10 February 2021).

32. PEC-Soil. Available online: https://english.ctgb.nl/documents/assessment-framework-ppp/2017/12/22/calculation-of-pecsoil-values (accessed on 10 February 2021).

33. WHO. Environmental Health Criteria 91: Aldrin and Dieldrin. Available online: http://www.inchem.org/documents/ehc/ehc/ ehc91.htm (accessed on 12 January 2021).

34. James, T.; Gaw, S. Available online: https://envirolink.govt.nz/assets/Envirolink/1472-TSDC103-Review-of-potential-soilcontamination-issues-from-pesticide-use-in-productive-land-and-sports-fields.pdf (accessed on 12 January 2021).

35. US-EPA. US EPA (United States Environmental Protection Agency). Mid Atlantic Risk Assessment. Regional Screening Level (RSL) Summary Table; US-EPA: Washington, DC, USA, 2013.

36. Niu, L.; Xu, Y.; Xu, C.; Yun, L.; Liu, W. Status of phthalate esters contamination in agricultural soils across China and associated health risks. Environ. Pollut. 2014, 195, 16-23. [CrossRef] [PubMed]

37. Li, Q.; Lu, Y.; Wang, P.; Wang, T.; Zhang, Y.; Suriyanarayanan, S.; Liang, R.; Baninla, Y.; Khan, K. Distribution, source, and risk of organochlorine pesticides (OCPs) and polychlorinated biphenyls (PCBs) in urban and rural soils around the Yellow and Bohai Seas, China. Environ. Pollut. 2018, 239, 233-241. [CrossRef] [PubMed]

38. Pesticides-TMDL. Molalla-Pudding Subbasin TMDL Chapter 4 Pesticides. Available online: https://www.oregon.gov/deq/ FilterDocs/MoPudChapter4Pesticides.pdf (accessed on 10 January 2021).

39. BOOK. Handbook of Environmental Fate and Exposure Data: For Organic Chemicals, 3rd ed.; Howard, P.H., Michalenko, E.M., Jarvis, W.F., Basu, D.K., Sage, G.W., Meylan, W.M., Beauman, J.A., Anthony Gray, D., Eds.; CRC Press: Boca Raton, FL, USA, 1991 ; p. 712. [CrossRef] 
40. Tox-Profile. Toxicological Profile for Aldrin/Dieldrin. U.S. Department of Health and Human Services, Public Health Service. Agency for Toxic Substances and Disease Registry. Available online: https:/ / www.atsdr.cdc.gov/toxprofiles/tp1.pdf (accessed on 10 January 2021).

41. FAO. Assessing Soil Contamination—A Reference Manual; FAO: Rome, Italy, 2000; Available online: http:/ /www.fao.org/3/X257 0E/X2570E00.htm (accessed on 10 February 2021).

42. Kah, M.; Beulke, S.; Brown, C.D. Factors influencing degradation of pesticides in soil. J. Agric. Food Chem. 2007, 55, 4487-4492. [CrossRef]

43. Qu, C.; Sun, Y.; Albanese, S.; Lima, A.; Sun, W.; Di Bonito, M.; Qi, S.H.; De Vivo, B. Organochlorine pesticides in sediments from Gulfs of Naples and Salerno, Southern Italy. J. Geochem. Explor. 2018, 195, 87-96. [CrossRef]

44. Qu, C.; Albanese, S.; Lima, A.; Li, J.; Doherty, A.L.; Qi, S.; De Vivo, B. Residues of hexachlorobenzene and chlorinated cyclodiene pesticides in the soils of the Campanian Plain, southern Italy. Environ. Pollut. 2017, 231, 1497-1506. [CrossRef]

45. Newton, I. Changes in the status of the Peregrine Falcon in Europe: An overview. Peregrine Falcon Popul. Manag. Recovery 1988, 227, 1982-1986.

46. Qu, C.; Albanese, S.; Li, J.; Cicchella, D.; Zuzolo, D.; Hope, D.; Cerino, P.; Pizzolante, A.; Doherty, A.L.; Lima, A.; et al. Organochlorine pesticides in the soils from Benevento provincial territory, southern Italy: Spatial distribution, air-soil exchange, and implications for environmental health. Sci. Total Environ. 2019, 674, 159-170. [CrossRef]

47. ONCGSCI. Office of the National Coordination Group for Stockholm Convention Implementation. In The People's Republic of China National Implementation Plan for the Stockholm Convention on Persistent Organic Pollutants; China Environment Science Press: Beijing, China, 2009.

48. US-EPA. Guidance for Developing Ecological Soil Screening Levels. (OSWER Directive 9285.7-55); Office of Solid Waste and Emergency Response: Washington, DC, USA. Available online: https:/ / rais.ornl.gov/guidance/epa_eco.html (accessed on 2 November 2020).

49. Weisgerb, I.; Kohli, J.; Kaul, R.; Klein, W.; Korte, F. Fate of Aldrin-C-14 in Maize, Wheat, and Soils under Outdoor Conditions. J. Agric. Food Chem. 1974, 22, 609-612. [CrossRef] [PubMed] 